eCAM 2009;6(1) 1-2

doi: $10.1093 /$ ecam/nep008

\title{
Editorial
}

\section{eCAM: Clinical Analyses and Increasing Visibility}

\section{Edwin L. Cooper}

Laboratory of Comparative Neuroimmunology, Department of Neurobiology and David Geffen School of Medicine at UCLA, University of California Los Angeles, Los Angeles, CA, USA

When $e C A M$ was first born in 2004 we recognized our role in the world of integrative medicine, which is to become the model publication devoted to evidence-based approaches, thus the name 'evidence based'. Recognition was given to the fact that $e C A M$ is a part of a larger compendium of information, technologies and ideas that increasingly overlap and intertwine in a tangled web of biological processes. There are sometimes interfacing and even colliding influences that include the forces of culture, habits and attitudes that can often snuff out, smother or mask the urgencies of viewing phenomena as biological or biomedical. Yet a crucial view prevails: we seek to fine-tune approaches that could yield analyses of evidence and ultimately to define mechanisms. Certain chronic ailments, but perhaps not acute problems, are the ripest for this modern excursion into integrative medicine.

In my first editorial, I proposed that $e C A M$, when rigorous, can be science (1). Happily, this created a stir and the beginnings of a barrage of invitations to somewhat exotic nations that are the cradles of integrative approaches: Ayurveda (2-4), Traditional Chinese Medicine (TCM) (5-7), Kampo (8-10) and Traditional Arabic and Islamic Medicine $(11,12)$. These travels were both inspiring, enlightening and a source for viewing integrative medicine in the larger human and multicultural context. With a constant vision of $e C A M$ as a spin-off from biology, I assumed that the publication of rigorously reviewed papers could be mixed, i.e. those dealing strictly with animal models (basic science) and human trials (clinical analyses), both of which often involve in vitro approaches. I held this view through volumes 1-3. However, in volume 4, I decided to perhaps change the focus of reader's attention and to accomplish this, I chose to group the basic science papers together and the clinical analyses together, maintaining the subjects but as distinct and separate categories - nothing wrong with that! We classify all the time, art, music, animals, plants, cultures, etc. In addition, I've published our first supplement (13).

However, I did have another vision and that was to determine if this separation might draw readers' attention to the need for and the active recruiting of clinical papers. After all eCAM's title says it all: 'evidence based' complementary and alternative medicine. So the instructions to authors were rewritten to include quite detailed ways to present clinical data (brief case reports; to develop case reports with detailed, illustrative documentation; case reports expanded into hypotheses; clinical studies with as strong an evidence base as possible, etc.) (14). Moreover, there were other efforts. I was invited to present Writer's Workshops at several national meetings of the American College for Advancement in Medicine (15-18), opening the doors for the works of clinicians. Instructions in $e C A M$ and Writers' Workshops were international, national and local. Moreover, there were policy-structured international efforts in conjunction with the World Health Organization (19). These were meetings designed exclusively for veterinarians recognizing the utility of animal models in the quest to understand human disease (20-22).

Now, here are the results of this five-year strategy, mixing and separating basic science and clinical analyses in volumes 1-5. From a cursory examination, there seemed to be no significant differences in the numbers of basic science papers vis-á-vis the clinical analyses in volumes 1-3. In volume 4 however, there was twicehigher the number of basic science papers compared with clinical analyses. It was with volume 4 that the first separation began and that situation has prevailed in volume 5. Thus, despite efforts to raise the number and quality of clinical submissions, it seems that basic science papers outnumber the clinical papers in the two most recent volumes 4 and 5 of $e C A M$, where there was the separation and, presumably, greater visibility. This raises 
the question-do authors view $e C A M$ as devoted more to basic science and to do credible work is easier in that sphere to accomplish than clinical approaches?

Now with volume 6, I question whether this seeming trend (i.e. toward more basic science papers) in $e C A M$ is a reflection of a national and international trend. Was $e C A M$ 's vision to recognize itself as a scientific journal that lays a foundation for clinical analyses the appropriate and meaningful way to visualize itself? Despite this covert attempt in comparison with the more direct ones, do the rigors and flavors of science dominate and embellish eCAM's strength and existence (23)?

Fortunately, the magazine Science may have a partial answer and present clues to questions surrounding clinical papers (Science 322: \#5899: 149-328; October $10,2008)$. Biomedical funding is in trouble and that is a cause for alarm in preparing our world's scientists. However, I have been struck by a strong publication devoted to the subject of clinical applications in a special issue: 'Clinical Trials and Tribulations'. This opens with an introduction by Eliot Marshall entitled 'Lemons, Oranges and Complexity'. A provocative cover shows a white-coated investigator pushing a gargantuan white pill up a mountain. Upon first seeing it, one is not clear if the mountain is made of blue rocks or piles of blue paper - in either case, in my opinion, piles of papers (qua bureaucracy) are as difficult to surmount or conquer as piles of rocks! According to the description of the cover: 'Steep terrain': to move a therapy from the research lab to the doctor's office requires a huge investment in clinical trials, which are growing more costly and more complex every year. Five pertinent topics are treated and online material can be viewed at: www.sciencemag.org/ clinicaltrials. So for $e C A M$, it seems that a clear message may be emerging. There is a continuing place for basic science and for clinical analyses. Basic science under girds the successful attempt at translation from the bench to the clinic. We need it all: animal models, in vitro assays and carefully monitored clinical applications. At the same time, there should be an ever reminder of the paper of Goldrosen and Strauss (24) that presented the pyramid: the base or foundation, case reports and the pinnacle: randomized, controlled, double-blinded trials. This is an essential hierarchy in approaching biomedical research.

\section{References}

1. Cooper EL. Complementary and alternative medicine, when rigorous, can be science. Evid Based Complement Alternat Med 2004;1:1-4.

2. Mashelkar RA. Second World Ayurveda Congress (Theme: Ayurveda for the Future)-Inaugural Address: Part I. Evid Based Complement Alternat Med 2008;5:129-31.

3. Mashelkar RA. Second World Ayurveda Congress (Theme: Ayurveda for the Future) - Inaugural Address: Part II. Evid Based Complement Alternat Med 2008;5:243-5.

4. Mashelkar RA. Second World Ayurveda Congress (Theme: Ayurveda for the Future)-Inaugural Address: Part III. Evid Based Complement Alternat Med 2008;5:367-9.
5. Liao H, Banbury LK, Leach DN. Antioxidant activity of 45 Chinese herbs and the relationship with their TCM characteristics. Evid Based Complement Alternat Med 2008:5:429-34.

6. Wang L, Muxin G, Nishida H, Shirakawa C, Sato S, Konishi T. Psychological stress-induced oxidative stress as a model of subhealthy condition and the effect of TCM. Evid Based Complement Alternat Med 2007;4:195-202.

7. Xia R, Huang P, Shao G. Nourishing Yin and promoting blood circulation of TCM to treat hemorheologic disorder induced by diabetes mellitus in rats. Evid Based Complement Alternat Med 2007;4:203-7.

8. Hijikata Y, Miyamae Y, Takatsu H, Sentoh S. Two Kampo Medicines, Jidabokuippo and Hachimijiogan Alleviate Sprains, Bruises and Arthritis. Evid Based Complement Alternat Med 2007;4:463-7.

9. Murayama T, Yamaguchi N, Matsuno H, Eizuru Y. In vitro anticytomegalovirus activity of kampo (Japanese Herbal) medicine. Evid Based Complement Alternat Med 2004;1:285-9.

10. Kiyohara H, Nagai $T$, Munakata $K$, Nonaka $K$, Hanawa $T$, Kim SJ, et al. Stimulating effect of Japanese Herbal (Kampo) medicine, hochuekkito on upper respiratory mucosal immune system. Evid Based Complement Alternat Med 2006;3:459-67.

11. Azaizeh H, Saad B, Cooper EL, Said O. Traditional Arabic and Islamic medicine, a re-emerging health aid. Evid Based Complement Alternat Med. (Advance Access published 13 June 2008) doi:10.1093/ecam/nen039.

12. Said O, Saad B, Fulder S, Khalil K, Kassis E. Weight loss in animals and humans treated with 'weighlevel', a combination of four medicinal plants used in traditional Arabic and Islamic medicine. Evid Based Complement Alternat Med. (Advance Access published 24 October 2008) doi:10.1093/ecam/nen067.

13. Cooper EL, Editor-in-chief. Evid Based Complement Alternat Med 2007;4(Suppl.);1-70.

14. Evidence-based Complementary and Alternative Medicine: Instructions for authors. http://www.oxfordjournals.org/our_journals/ ecam/for_authors/instauth1.html.

15. Feig SA, Speight N, Hynote E, Magaziner A. Summary of the American College for Advancement in Medicine, November 2004 Conference on Emerging Concepts in Immunology. Evid Based Complement Alternat Med 2005;2:121-4.

16. Feig SA, Hynote E, Speight N, Magaziner A, Miranda RA, Schachter MB. Summary of the American College for Advancement in Medicine, May 2005 Conference: Menopause, Andropause: Power in Transition. Evid Based Complement Alternat Med 2005;2:413-9.

17. Feig SA, Biddle J, Hynote E, Speight N, Bock K, Magaziner A, Rich JE. Summary of the American College for Advancement in Medicine, November 2005 Conference on Scientific Integrative Medicine: Advancing Health Horizons. Evid Based Complement Alternat Med 2006;3:385-91.

18. Speight N, Hynote ED. Summary of the American College for Advancement in Medicine, November 2007 Conference on Integrative Medicine: Advancing Science and Clinical Practice. Evid Based Complement Alternat Med. (Advance Access published 20 March 2008) doi:10.1093/ecam/nen020.

19. Cooper EL. Meeting Report: 12th International Congress of Oriental Medicine. Evid Based Complement Alternat Med 2004;1:103-6.

20. Rastogi S, Kaphle K. Sustainable traditional medicine: taking the inspirations from ancient veterinary science. Evid Based Complement Alternat Med. (Advance Access published 2 November 2008) doi:10.1093/ecam/nen071.

21. Kaphle K, Wu Y, Lin J. Thirtieth Annual Congress on Veterinary Acupuncture: IVAS Report. Evid Based Complement Alternat Med 2005;2:239-42.

22. Lin J, Shih C, Kaphle K, Wu L, Tseng W, Chiu J, et al. Acupuncture effects on cardiac functions measured by cardiac magnetic resonance imaging in a feline model. Evid Based Complement Alternat Med. (Advance Access published 23 January 2008) doi:10.1093/ecam/nem187.

23. Paul PG. E-letter for bioprospecting: a CAM frontier. http:// ecam.oxfordjournals.org/cgi/eletters/2/1/1.

24. Goldrosen MH, Strauss SE. Complementary and alternative medicine: assessing the evidence for immunological benefits. Nat Rev Immunol 2004;4:912-21. 


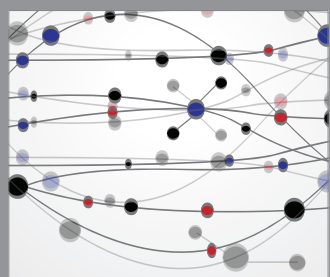

The Scientific World Journal
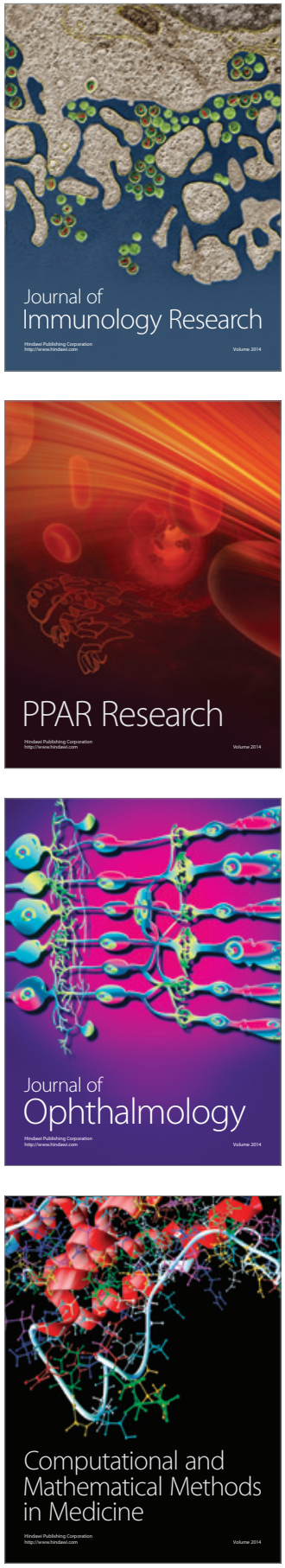

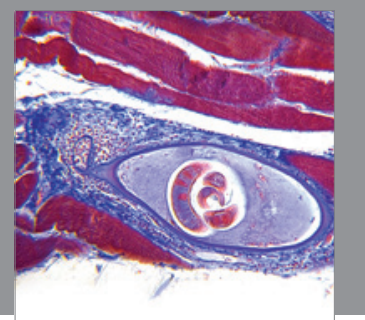

Gastroenterology

Research and Practice
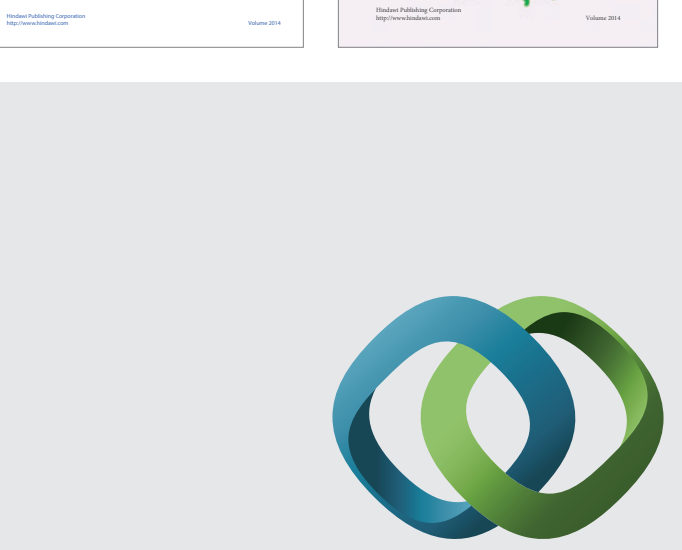

\section{Hindawi}

Submit your manuscripts at

http://www.hindawi.com
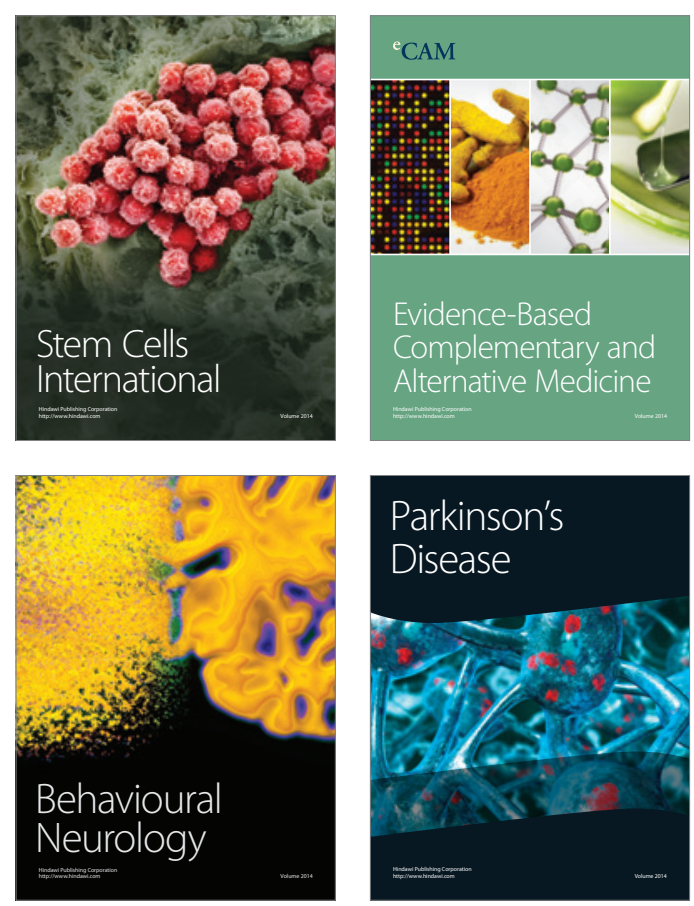

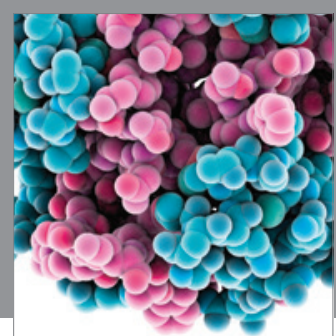

Journal of
Diabetes Research

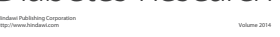

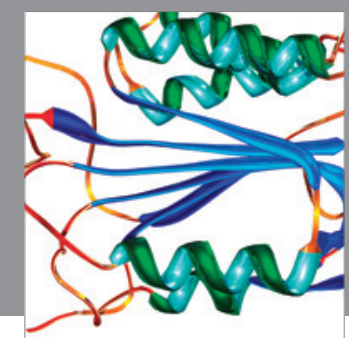

Disease Markers
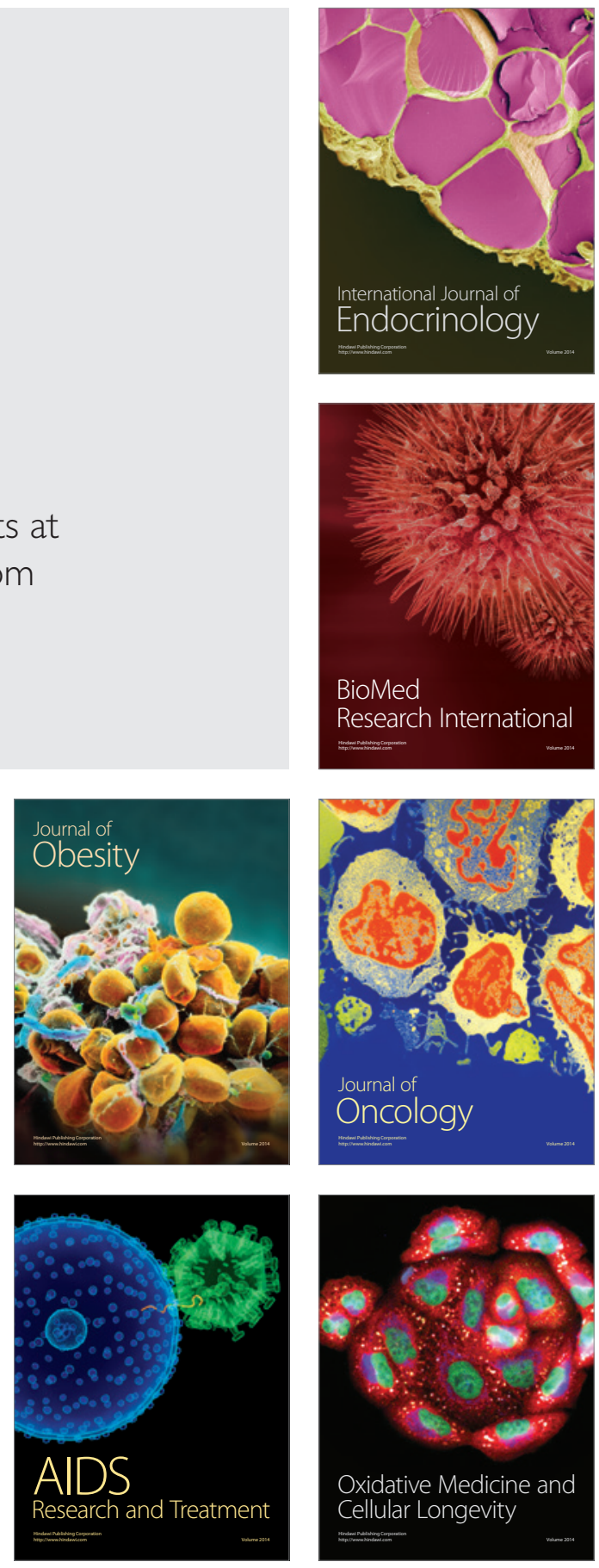